\title{
Current Hospital Demographics of Subarachnoid Hemorrhage Based on CT Angiography and 3D Rotational Angiography in a Neurosurgical Center
}

\author{
(D)S.B.T. van Rooij, (DR.S. Bechan, (D)W.J. van Rooij, and (DM.E. Sprengers
}

\begin{abstract}
BACKGROUND AND PURPOSE: Aneurysmal subarachnoid hemorrhage is an important cause of mortality and morbidity. Modern hospital demographics are scarce. We evaluated the diagnosis and treatment of patients with SAH in a neurosurgical referral center.

MATERIALS AND METHODS: Between March 2013 and April 2015, two hundred eighty-four patients with SAH diagnosed on CT or lumbar puncture were admitted. All patients underwent 64 - to 128 -detector row CT angiography. Additional imaging was with 3D rotational angiography of all vessels. In patients with aneurysms, characteristics and mode of treatment were recorded.

RESULTS: In 197 of 220 patients with an aneurysmal bleeding pattern, we found a cause of the bleeding: One hundred ninety-five patients had a ruptured aneurysm (98\%); 1 patient, a micro-AVM; and 1 patient, reversible vasoconstriction syndrome. Of 195 ruptured aneurysms, 6 were dissecting aneurysms and 3 were AVM-associated flow aneurysms. In 23 of 204 patients (11\%) with an aneurysmal bleeding pattern and 3D rotational angiography performed, no cause was found. In 8 of 9 patients (89\%) with lumbar puncture positive for SAH but CT negative for it, no cause was found. Of 180 patients with a ruptured aneurysm eligible for treatment, 147 (82\%) were treated endovascularly and 30 aneurysms (17\%) were clipped. Of 204 patients with an aneurysmal bleeding pattern and 3D rotational angiography, 72 (35\%) had multiple aneurysms. These 72 patients had, altogether, 117 additional aneurysms, of which 24 (21\%) were treated by either coiling or clipping.
\end{abstract}

CONCLUSIONS: This study provides robust data on hospital demographics of SAH in a neurosurgical referral center, based on CTA and $3 \mathrm{D}$ rotational angiography of all vessels.

ABBREVIATION: 3DRA $=3$ rotational angiography

A neurysmal subarachnoid hemorrhage is an important cause of mortality and continuing morbidity in the population worldwide. The annual incidence of SAH in Western Europe and North America is 6-8 per 100,000 person-years. ${ }^{1}$ More than $30 \%$ of patients with aneurysmal SAH will die within the first 24 hours, and another $25 \%-30 \%$ will die in the following 4 weeks without some form of intervention. ${ }^{1}$ Hospital demographics of SAH have dramatically changed in the past 2 decades. With endovascular techniques, more aneurysms in more patients can be treated than in the era when surgical clipping was the only treatment tech-

Received February 7, 2019; accepted after revision April 4.

From the Department of Radiology (S.B.T.v.R.), Noordwest Zlekenhuisgroep Alkmaar, the Netherlands; Universitair Medisch Centrum Amsterdam (R.S.B.), Vrije Universiteit, Amsterdam, the Netherlands; Algemeen Ziekenhuis Turnhout (W.J.v.R.), Turnhout, Belgium; and Universitair Medisch Centrum Amsterdam (M.E.S.), Academisch Medisch Centrum, Amsterdam, the Netherlands.

Please address correspondence to S.B.T. van Rooij, MD, Department of Radiology, Noordwest Zlekenhuisgroep Alkmaar, Wilhelminalaan 12, 1815JD Alkmaar, the Netherlands; e-mail: s.b.t.rooij@gmail.com

http://dx.doi.org/10.3174/ajnr.A6060 nique. Aneurysm diagnosis has immensely improved with acute CTA screening and the implementation of 3D angiographic techniques. $^{2-4}$ This results in detection of more and smaller ruptured and (additional) unruptured aneurysms. In this study, we prospectively collected demographic, diagnostic, and treatment data of patients admitted with SAH in a 2-year period in the St Elisabeth Hospital in Tilburg, the Netherlands, a large neurosurgical referral center.

\section{MATERIALS AND METHODS Patient Population}

This observational study with prospectively collected data was compliant with institutional privacy policy and approved by the institutional review board. Between March 2013 and April 2015, patients with SAH on native CT scans or with lumbar puncture positive for SAH and who underwent CTA were entered into a data base, as previously described. ${ }^{3,4}$ The St. Elisabeth Hospital in Tilburg, the Netherlands, is a large neurosurgical referral center with a recruitment population of 2.5 million and is a Level I trauma center. 
Patients were categorized according to medical history and blood distribution on CT as having aneurysmal SAH, perimesencephalic SAH, trauma and SAH, no blood on CT, and a lumbar puncture positive for SAH (xanthochromia). A perimesencephalic bleeding pattern was defined as blood confined to the cisterns around the midbrain in the prepontine, interpeduncular, and ambient cisterns. Patient and aneurysm characteristics and modes of treatment were recorded.

\section{CT Angiography}

CTA was performed on 1 of 3 CT scanners: Brilliance iCT 256detector row, Ingenuity 128-detector row (Philips Healthcare, Best, the Netherlands) and Somatom Definition AS 64-detector row (Siemens, Erlangen, Germany). Volume CT was routinely performed at $130 \mathrm{~mA}$ and $100-120 \mathrm{kV}$ (peak). Collimation, rotation time, and pitch were optimized for the individual CT scanner according to recommendations of the manufacturer. A $90-\mathrm{mL}$ dose of iodinated contrast medium (iodixanol, $270 \mathrm{mg}$ of iodine/ mL, Visipaque 270; GE Healthcare, Piscataway, New Jersey) was injected at a rate of $4.0 \mathrm{~mL} / \mathrm{s}$ into an antecubital vein via a 20 -ga catheter, followed by $40 \mathrm{~mL}$ of saline solution. CT scanning was triggered using a bolus-tracking technique, with the ROI placed in the aortic arch. Image acquisition started 8 seconds after the attenuation reached the predefined threshold of 130-150 HU. The scanning time was approximately 5.0-7.0 seconds. Images were reconstructed with a 0.9 - to $1.0-\mathrm{mm}$ section thickness and a 0.45 - to 0.5 -mm increment. Volume CT dose index and doselength product were $25.3-26.7 \mathrm{mGy}$ and $475-576 \mathrm{mGy} \times \mathrm{cm}$, respectively.

\section{D Rotational Angiography}

Patients with aneurysms diagnosed on CTA or with CTA negative for SAH but an aneurysmal bleeding pattern underwent 3D rotational angiography (3DRA) of all cerebral vessels. Angiography was performed on a biplane angiographic system (Allura Xper FD 20/10; Philips Healthcare). In uncooperative or intubated patients, 3DRA was performed with the patient under general anesthesia. A single 3D rotational angiographic run was acquired of both internal carotid arteries and 1 vertebral artery with a hand injection of 12-20 mL of contrast material. When the contralateral distal vertebral artery was not visualized, an additional 2D biplane run was performed of this vertebral artery. The tube rotation arc was $240^{\circ}$ ( 1 rotation used), with a rotation time of 4.1 seconds. The images were reconstructed in a $256 \times 256$ matrix. The rotational angiographic data were transferred to an independent workstation (Integris 3DRA Workstation; Philips Healthcare) for instant generation of 3D reformatted images.

\section{Analysis of CT Angiography and 3D Rotational Angiography}

CTA data were reformatted on an independent 3D workstation (IntelliSpace Portal; Philips Healthcare). Three neuroradiologists evaluated maximum-intensity-projection, volume-rendered, and multiplanar reformatted images. Source images, postprocessed images, and 3D reconstructions with bone removal were transferred to a PACS.

3DRA reformatted images were reviewed on the workstation by the first and senior authors in consensus. The presence, location, and size of aneurysms were recorded in a data base. Other vascular disorders that might be responsible for the subarachnoid hemorrhage such as arterial dissections, arteriovenous malformations, Moyamoya phenomenon, or reversible vasospasm syndrome were separately recorded. In patients without an obvious vascular disorder that might be responsible for the SAH, 3DRA was repeated after 1 week. ${ }^{4}$

\section{Treatment}

When logistically possible, 3DRA was followed immediately by endovascular treatment, with the patient under general anesthesia. Patients with aneurysms not suitable for coiling (wide-neck anterior circulation, fusiform, vessels arising from the sac) were scheduled for surgery. When logistically possible, good-grade (noncomatose) patients were clipped within 24 hours. In poorgrade patients, the operation was delayed.

\section{Statistical Analysis}

Results were expressed with descriptive statistics, and categoric variables, as frequencies or percentages with $95 \%$ CIs.

\section{RESULTS}

Of 284 patients with SAH, 220 (77\%) had an aneurysmal bleeding pattern, 39 (14\%) had a perimesencephalic bleeding pattern, 9 (3\%) had CT for SAH and a lumbar puncture positive for SAH, and $16(6 \%)$ had a trauma and a subarachnoid hemorrhage.

Of 284 patients, 280 underwent CTA as the first diagnostic technique to detect the cause of the SAH. Four patients with SAH directly proceeded to angiography without CTA. The Figure illustrates the diagnosis and treatment of the study population in a flow chart.

\section{Aneurysmal Bleeding Pattern}

Of 220 patients with an aneurysmal bleeding pattern, 16 patients with confirmed aneurysms on CTA (7\%) were in moribund clinical condition and died before angiography could be performed.

The remaining 204 patients had 3DRA after CTA. In 29 of 204 patients (14\%), the initial 3DRA was negative for SAH and was repeated after 1 week. Repeat 3DRA showed an aneurysm in 6 of these 29 patients: one 8-mm supraclinoid dissecting aneurysm, 2 superior cerebellar artery aneurysms ( 1 and $2 \mathrm{~mm}$ ), one 2-mm posterior communicating aneurysm, one 1-mm A1 aneurysm, and 1 vertebral dissection.

In 195 of 220 patients with an aneurysmal bleeding pattern (87\%; 95\% CI, 84\%-92\%), at least 1 aneurysm was detected. Seventy-two of 204 patients with 3DRA (35\%; 95\% CI, 29\%-42\%) had multiple aneurysms. Forty-three patients had 2 aneurysms, 18 patients had 3 aneurysms, 10 patients had 4 aneurysms, and 1 patient had 5 aneurysms.

Of 220 patients with an aneurysmal bleeding pattern, 184 had saccular aneurysms, 6 had a dissecting aneurysm (1 PICA, 3 vertebral artery, and 2 internal carotid artery aneurysms), and 3 patients had an AVM-related ruptured flow aneurysm.

Of the 25 patients with aneurysmal SAH and no aneurysm, 1 patient $(0.5 \%)$ had a cervical spinal micro-AVM and 1 patient $(0.5 \%)$ had a reversible vasoconstriction syndrome. In 23 of 220 


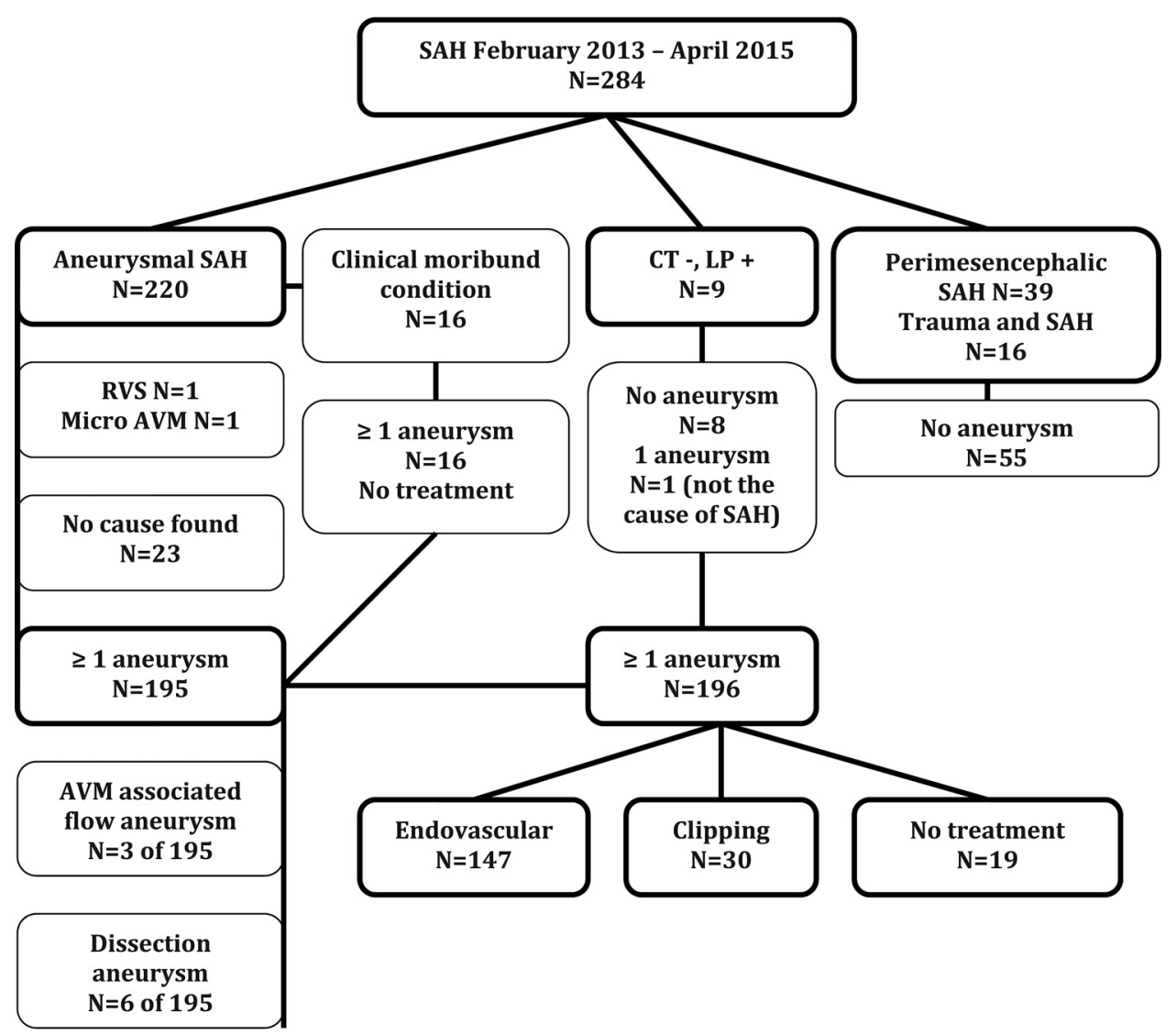

FIGURE. Diagnosis and treatment in 284 consecutive patients with SAH. RVS indicates reversible vasospasm syndrome; LP, lumbar puncture.

patients with aneurysmal SAH (10\%; 95\% CI, 7\%-15\%), no aneurysm or other vascular disorder was found.

\section{Perimesencephalic Bleeding Pattern}

Of 284 patients, 39 (14\%; 95\% CI, 10\%-18\%) had a perimesencephalic bleeding pattern on native CT. Fifteen of 39 underwent 3DRA in addition to CTA. CTA and 3DRA were negative for aneurysms in all 39.

\section{Positive Lumbar Puncture Findings}

Of 284 patients, 9 (3\%) had no blood on CT but had a lumbar puncture positive for xanthochromia. All 9 underwent CTA, and 2 patients also had 3DRA. In 1 patient, a 7-mm dysplastic fusiform middle cerebral artery aneurysm was found that was not considered the cause of the SAH.

\section{Trauma and SAH}

Of 284 patients, $16(6 \%)$ had trauma and SAH and an unknown cause and effect. CTA findings were normal in all 16 patients.

\section{Treatment}

Ruptured Aneurysm Treatment. Of 180 patients eligible for treatment with a ruptured aneurysm (including 6 dissecting aneurysms), in $147(82 \%)$, this aneurysm was treated endovascularly. Of 141 saccular aneurysms, 115 (82\%) were treated with simple coiling; 24 (17\%), with balloon- or stent-assisted coiling; and 2 (1\%), with an intrasaccular flow disrupter (WEB aneurysm embolization system; Sequent Medical, Aliso Viejo, California).
Of 6 dissecting aneurysms, 3 vertebral dissections and 1 PICA dissection were treated with parent vessel coil occlusion. Of 2 internal carotid artery dissecting aneurysms, 1 was treated with stent-assisted coiling and the other with a flow diverter. Of 3 patients with a ruptured AVM-related flow aneurysm, 2 were treated with parent vessel coil occlusion; and 1, with selective coiling. Of 180 patients with a ruptured aneurysm, 30 aneurysms (17\%) were clipped.

\section{Characteristics of Patients with Endovascularly Treated- versus-Clipped Aneurysms}

Patient and aneurysm characteristics of those with endovascularly treated and clipped aneurysms are shown in the Table. Reasons to proceed with an operation instead of endovascular treatment in 30 patients were wide-neck aneurysms in 27 , failed coiling procedure in 2 , and no endovascular access in 1.

\section{Patients Who Were Not Treated}

Nineteen of 196 patients with a saccular aneurysm (10\%) were not treated: Sixteen patients were in a clinically moribund condition, and 3 patients were older than 90 years of age. It was decided not to treat the cervical micro-AVM.

\section{Timing of Treatment}

The mean time between the ictus and endovascular treatment was 1 day (median, 1 day; range, $0-20$ days). The mean time between diagnosis and endovascular treatment was 1 day (median, 0 days; range, $0-11$ days). Reasons for a delay between ictus and endo- 
Clinical variables at admission of patients with ruptured aneurysms eligible for treatment

\begin{tabular}{|c|c|c|}
\hline & $\begin{array}{l}\text { Endovascular } \\
(n=147)(82 \%)\end{array}$ & $\begin{array}{c}\text { Surgery } \\
(n=30)(17 \%)\end{array}$ \\
\hline Age (yr) & $\begin{array}{l}\text { Mean, 58; } \\
\text { median, 58; } \\
\text { range, 27-86 }\end{array}$ & $\begin{array}{l}\text { Mean, 58; } \\
\text { median, 59; } \\
\text { range, 28-84 }\end{array}$ \\
\hline Sex & 106 Female (72\%) & 23 Female (77\%) \\
\hline \multicolumn{3}{|l|}{$\mathrm{HH}$ at admission } \\
\hline 1 & 54 & 11 \\
\hline 2 & 22 & 8 \\
\hline 3 & 33 & 4 \\
\hline 4 & 21 & 6 \\
\hline 5 & 17 & 1 \\
\hline \multicolumn{3}{|l|}{ Aneurysm size } \\
\hline$\leq 3 \mathrm{~mm}$ & 25 & 13 \\
\hline $4-6 \mathrm{~mm}$ & 63 & 9 \\
\hline $7-10 \mathrm{~mm}$ & 39 & 6 \\
\hline$\geq 10 \mathrm{~mm}$ & 20 & 2 \\
\hline \multicolumn{3}{|l|}{ Aneurysm location (No.) } \\
\hline Anterior cerebral artery & 61 & 17 \\
\hline Middle cerebral artery & 21 & 8 \\
\hline Internal carotid artery & 43 & 3 \\
\hline Posterior circulation & 22 & 2 \\
\hline
\end{tabular}

Note:- $-\mathrm{HH}$ indicates Hunt and Hess scale.

vascular treatment were admission or referral from other hospitals several days after the ictus, clinical condition that did not allow angiography directly after admission, or initial negative findings on angiography. Most patients (111 of 146, 76\%) were treated within 24 hours after the ictus. The mean time between the ictus and clipping was 10 days (median, 9 days; range, 0-31 days). The mean time between diagnosis of the ruptured aneurysm and clipping was 8 days (median, 8 days; range, $0-30$ days).

\section{Treatment of Additional Aneurysms}

Of the 204 patients with an aneurysmal bleeding pattern and 3DRA, 72 (35\%) had multiple aneurysms. These 72 patients had, altogether, 117 additional aneurysms, indicating a mean of 1.6 bystander aneurysms next to the index aneurysm. Of these 117 additional aneurysms, 24 (21\%) were treated by either coiling or clipping.

\section{DISCUSSION}

In this prospective observational study, we found that in $69 \%$ of patients with SAH (195 of 284), a ruptured aneurysm was the cause. This is much lower than in the literature of the early millennium with a ruptured aneurysm as cause of SAH in $85 \%$. Our incidence is lower because of zero yield of aneurysms in patients with a perimesencephalic bleeding pattern, with trauma and $\mathrm{SAH}$, and with $\mathrm{CT}$ negative/lumbar puncture positive for SAH. Of 220 patients with an aneurysmal bleeding pattern on CT, an aneurysm was found in 195 (89\%) and no cause was found in 23 (10\%), not even after repeat 3D angiography.

In our study, 39 of 284 patients (14\%) had a perimesencephalic bleeding pattern on native CT. CTA was negative for aneurysms in all 39. Fifteen of 39 underwent 3DRA in addition to CTA, all negative for aneurysms. The cause of perimesencephalic hemorrhage is likely not aneurysmal but may be venous, and the patients have no risk of rebleed. ${ }^{7-9}$ Cerebral angiography is not needed in patients with perimesencephalic hemorrhage who had negative CTA findings. ${ }^{10}$
Multiple aneurysms were found in 72 of the 204 patients (35.3\%) with an aneurysmal bleeding pattern and 3DRA performed. These 72 patients had, altogether, 117 additional aneurysms, indicating a mean of 1.6 bystander aneurysms. These figures are in the same range as in a recent large Swiss study ${ }^{11}$ in which multiplicity was found in 474 of 1787 patients (26.5\%). Patients with multiple aneurysms had a mean of 1.4 bystander aneurysms in addition to the index aneurysm. In older postmortem and angiographic studies, a prevalence of multiplicity of about $12 \%$ was found, substantially less than in the current study. ${ }^{12}$ The excellent sensitivity for detecting aneurysms with $3 \mathrm{D}$ angiography indicates that multiplicity of intracranial aneurysms is on the order of 1 in 3 instead of 1 in 8 patients as previously believed.

Ruptured aneurysms were treated endovascular in $82 \%$; this proportion is relatively high compared with other reports. ${ }^{13} \mathrm{Al}$ though there have been several studies on changes and trends in the management of SAH since the publication of the International Subarachnoid Aneurysm Trial (ISAT), scarce data exist on the characteristics of patients undergoing surgical treatment. ${ }^{13-16}$ Most aneurysms in our population that were referred to surgery were anterior circulation wide-neck aneurysms with vessels coming from the sac. We found that most clipped aneurysms were anterior communicating artery aneurysms; this is in concordance with another study. ${ }^{14}$

AVM-associated flow aneurysms are a rare cause of SAH. ${ }^{15}$ In our study, 3 of 195 patients (1.5\%) with a ruptured aneurysm had an AVM-associated ruptured flow aneurysm. One AVM was supratentorial, and 2 AVMs were located in the posterior fossa. Posterior fossa AVMs are infrequent, comprising 7\%-15\% of intracranial AVMs. ${ }^{15}$ An infratentorial AVM location is independently associated with hemorrhagic AVM presentation. ${ }^{16}$ Dissecting aneurysms are also a rare cause of SAH. ${ }^{17,18}$ In our study, they were the cause of SAH in 6 of 195 patients (3\%).

In our study, 9 of 284 patients (3\%) had CT negative and lumbar puncture positive for SAH. In 1 of 9 patients, an aneurysm was found that was not considered the cause of hemorrhage. Another prospective study found, in 40 of 94 patients (43\%), an intracranial aneurysm or dissection. ${ }^{19}$ The small patient groups make the comparison invalid.

In our study, 16 of 284 patients $(6 \%)$ had trauma and SAH and an unknown cause and effect. CTA findings were normal in all 16 patients. In a recent retrospective study, 186 of 617 patients with traumatic SAH underwent CTA. The authors found 8 ruptured aneurysms; these patients all had blood in the subarachnoid cisterns and Sylvian fissures. They found 5 unruptured aneurysms; these patients had only peripheral subarachnoid blood. Their data suggest a more selective approach to screening CTAs in patients with trauma and SAH. ${ }^{14}$

Of note, our results are based on SAH demographics in a neurosurgical referral center and thus cannot be generalized to demographics of SAH in general.

\section{CONCLUSIONS}

Our study provides robust hospital demographic data on SAH based on CTA for screening and 3DRA of all cerebral vessels. The excellent depiction of aneurysms with 3DRA shows a shift of some 
data: Aneurysm multiplicity was on the order of 1 in 3 (instead of 1 in 8 ), and $11 \%$ of patients with an aneurysmal bleeding pattern on CT had no aneurysm, not even after repeat 3DRA.

Disclosures: Sanne B.T. van Rooij—UNRELATED: Grant: MicroVention, Comments: support of salary and travel expenses directly related to the study.

\section{REFERENCES}

1. Linn FH, Rinkel GJ, Algra A, et al. Incidence of subarachnoid hemorrhage: role of region, year, and rate of computed tomography-a meta-analysis. Stroke 1996;27:625-29 CrossRef Medline

2. van Rooij WJ, Sprengers ME, de Gast AN, et al. 3D rotational angiography: the new gold standard in the detection of additional intracranial aneurysms. AJNR Am J Neuroradiol 2008;29:976-79 CrossRef Medline

3. Bechan RS, van Rooij SB, Sprengers ME, et al. CT-angiography versus $3 \mathrm{D}$ rotational angiography in patients with subarachnoid hemorrhage. Neuroradiology 2015;57:1239-46 CrossRef Medline

4. Bechan RS, van Rooij WJ, Peluso JP, et al. Yield of repeat 3D angiography in patients with aneurysmal-type subarachnoid hemorrhage. AJNR Am J Neuroradiol 2016;37:2299-303 CrossRef Medline

5. van Gijn J, Rinkel GJ. Subarachnoid haemorrhage: diagnosis, causes and management. Brain 2001;124(Pt 2):249-78 CrossRef Medline

6. Van Gijn J, Kerr RS, Rinkel GJ. Subarachnoid haemorrhage. Lancet 2007:369:306-18 CrossRef Medline

7. Mensing LA, Vergouwen MD, Laban KG, et al. Perimesencephalic hemorrhage: a review of epidemiology, risk factors, presumed cause, clinical course, and outcome. Stroke 2018;49:1363-70 CrossRef Medline

8. Rinkel GJ, van Gijn J, Wijdicks EF. Subarachnoid hemorrhage without detectable aneurysms: a review of the causes. Stroke 1993;24: 1403-09 CrossRef Medline

9. van der Schaaf IC, Velthuis BK, Gouw A, et al. Venous drainage in perimesencephalic haemorrhage. Stroke 2004;35:1614-18 CrossRef Medline
10. Velthuis BK, Rinkel GJ, Ramos LM, et al. Perimesencephalic hemorrhage: exclusion of vertebrobasilar aneurysms with CT angiography. Stroke 1999;30:1103-09 CrossRef Medline

11. Roethlisberger M, Achermann R, Bawarjan S, et al; Swiss SOS group. Predictors of occurrence and anatomic distribution of multiple aneurysms in patients with aneurysmal subarachnoid hemorrhage. World Neurosurg 2018;111:e199-205 CrossRef Medline

12. Rinkel GJ, Djibuti M, Algra A, et al. Prevalence and risk of rupture of intracranial aneurysms: a systematic review. Stroke 1998;29:251-56 CrossRef Medline

13. Qureshi AI, Vazquez G, Tariq N, et al. Impact of International Subarachnoid Aneurysm Trial results on treatment of ruptured intracranial aneurysms in the United States: clinical article. J Neurosurg 2011;114:834-41 CrossRef Medline

14. Koźba-Gosztyla M, Czapiga B, Jarmundowicz W. Aneurismal subarachnoid hemorrhage: who remains for surgical treatment in the post-ISAT era? Arch Med Sci 2015;11:536-43 CrossRef Medline

15. Flett LM, Chandler CS, Giddings D, et al. Aneurysmal subarachnoid hemorrhage: management strategies and clinical outcomes in a regional neuroscience center. AJNR Am J Neuroradiol 2005;26:367-72 Medline

16. Arnaout OM, Gross BA, Eddleman CS, et al. Posterior fossa arteriovenous malformations. Neurosurg Focus 2009;26:E12 CrossRef Medline

17. Gonzalez AM, Narata AP, Yilmaz H, et al. Blood blister-like aneurysms: single center experience and systematic literature review. Eur J Radiol 2014;83:197-205 CrossRef Medline

18. Peluso JP, van Rooij WJ, Sluzewski, et al. Endovascular treatment of symptomatic intradural vertebral dissecting aneurysms. AJNR Am J Neuroradiol 2008;29:102-06 CrossRef Medline

19. Bakker NA, Groen RJ, Foumani M, et al. Appreciation of CT-negative, lumbar puncture-positive subarachnoid haemorrhage: risk factors for presence of aneurysms and diagnostic yield of imaging. J Neurol Neurosurg Psychiatry 2014;85:885-88 CrossRef Medline 